\title{
CHEMICAL CONTROL OF SHOT-HOLE BORER, XYLEBORUS FORNICATUS EICHH. (COLEOPTERA: SCOLYTIDAE) IN TEA
}

\author{
RS Walgama*, PD Senanayake, AR Abeysekera, AK Premathunge, R Perea, BS Vitana, B Sureshkumar and \\ C De Seram \\ Division of Entomology, Tea Research Institute, Talawakelle
}

Accepted: $7^{\text {th }}$ September 2008

\begin{abstract}
Chemical control is an integral component of the IPM programme of a key pest like shot-hole borer but it needs to be truly prophylactic. The currently recommended insecticides do not offer an adequate control though use as a prophylactic measure. This study investigates the level of control achieved with fenthion and fipronil and the implications of it. These insecticides if used at the correct time can provide only about $40 \%$ control over the untreated. The reduced gallery formation results in reduction in the subsequent population numbers and minimizes impact on tea from the new generation. The phenyl pyrazole insecticide, fipronil $50 \mathrm{SC}$, had to be withdrawn from the recommendation as a result of the very low MRL value stipulated by the tea buyers, which makes it difficult to use on tea.
\end{abstract}

Key words: chemical control, population dynamics, Tea shot-hole borer

\section{INTRODUCTION}

Shot-hole borer is one of the most serious pests of tea in Sri Lanka. The damage it causes is two fold where the primary damage is a result of constructing galleries in the branches and the most damaging, the accumulation of wood rot, which debilitates the bush in the long run. The difficulty in controlling due to its well-concealed habit, the economic damage it causes as well as the wide distribution (Walgama \& Pallemulla 2005), contributed it to be a key pest of tea.

Chemical control of shot-hole borer has been attempted since its discovery with varying degrees of success and it continues to date. Chemical control still plays an integral part in the Integrated Pest Management (IPM) of a key pest of this nature. Ideally, the chemical protection should be prophylactic, as the damage accumulates with time, if it is not prevented.

Highly potent organochlorine insecticides were replaced in 1985 by the organophosphate- fenthion with contact and stomach activity. The control given by this chemical found inadequate as compared to the organochlorine insecticides. Fipronil (a phenil pyrazole) with contact activity was also recommended for shot-hole borer but it was withdrawn as a result of very low Maximum Residue Levels (MRL) stipulated by the major tea buying countries (Walgama, 2006).

The degree of control achieved is mainly in the form of reducing the formation of galleries and consequently the corresponding decrease in population numbers. This results in reducing the impact from the new generations of shot-hole borer on tea. These two chemicals, fenthion and fipronil can be used as prophylactic treatments though the level of control achieved is in the range of $40-50 \%$. This paper describes the chemical control of shot-hole borer with these two chemicals, in the light of some experimental evidence obtained recently.

\section{MATERIALS AND METHODS}

The experiments were conducted at 4 locations in low and mid elevations (Table 1).The experimental area was planted to TRI 2025, the most susceptible cultivar to shot-hole borer, and about 17-18 months since the last prune. The experiments were laid in RCBD design with four treatments in three replicates (Table 2). Each plot consisted of 70 tea bushes. The selected fields were sampled to obtain the current shot-hole borer infestation levels in the pruning cycle. The fields were visually demarcated into one ha blocks and samples were taken in the manner described by Vitarana (2003).The experimental plots then were laid down in areas where the infestation levels were generally uniform. Fenthion at the recommended dosage $(4500 \mathrm{ml} / \mathrm{ha})$ was used as the standard

These treatments were applied on to the stems of bushes using a knapsack sprayer (16 litres) in such a way the stems were thoroughly wetted (total spray volume is $1,0001 / \mathrm{ha}$ ). Before the treatments, sampling was done to assess shot-hole borer infestation levels where 20 stems (about $1 / 4^{\text {th }}$ of the total bushes) of $30 \mathrm{~cm}$ in length were removed from bushes randomly from each plot. The stems removed in such manner were the primary branches, which have been originated from the last prune cut. Post treatment sampling was done once a month for a period of one year.

*Corresponding author 
Table 1. Experimental locations

\begin{tabular}{ccccc}
\hline $\begin{array}{c}\text { Location } \\
\text { (Estate) }\end{array}$ & $\begin{array}{c}\text { Major } \\
\text { region }\end{array}$ & AER & $\begin{array}{c}\text { Elevation } \\
(\mathbf{m})\end{array}$ & Lat./Long. \\
\hline Ury & $\begin{array}{c}\text { Mid country } \\
\text { (Dry zone) }\end{array}$ & IU3 (D) & $\sim 1120$ & $6 " 56 \mathrm{~N} / 81$ "07E \\
Madulkelle Mid country & IU1 & $\sim 745$ & 7 722N/80"45E \\
\hline
\end{tabular}

AER - Agro Ecological Region

The stems were brought to the laboratory and split open to record the following:

1. Number of stems infested

2. Total number of galleries (open, occupied and healed) in every sampled stem

3.Total population (eggs, larvae, pupae and adults) recovered from occupied galleries

Statistical analysis was done using PROC CATMOD (SAS 2003), population numbers were taken as the parameter for the analysis. The significance level was set at $\mathrm{p}<0.05$.

\section{RESULTS}

The characteristic population trend of shot-hole borer in a pruning cycle was seen where an increase in the numbers from about 17 months after prune, reaching a peak around 25 months after prune and then the typical decline after the peak (Fig. 1).

The results showed that the initial variation in

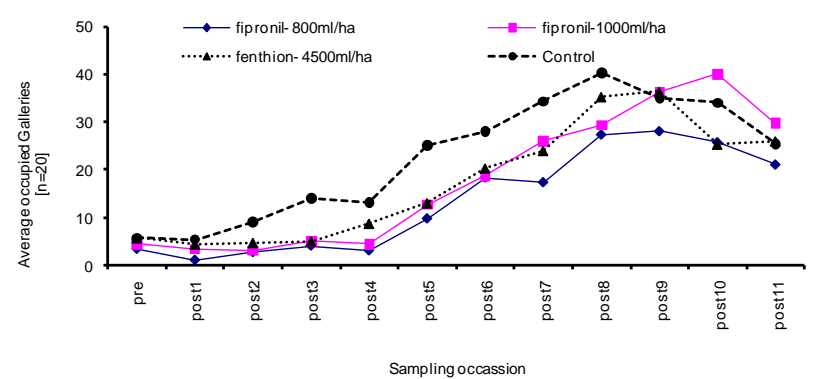

(a)

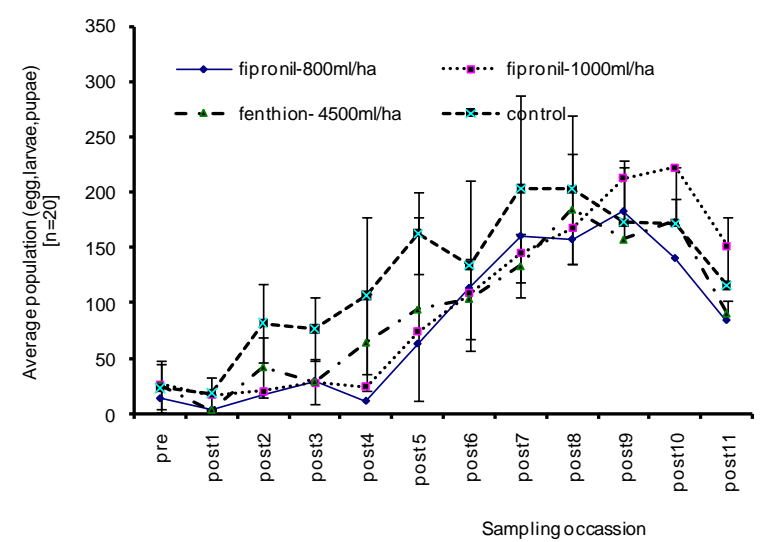

(b)
Table 2. Treatments tested

\begin{tabular}{lcc}
\hline \multicolumn{1}{c}{ Treatment } & $\begin{array}{c}\text { Dosage } \\
(\mathbf{m l} / \mathbf{h a})\end{array}$ & $\begin{array}{c}\text { Dilution } \\
(\mathbf{m l} / \mathbf{1 0} \text { L water })\end{array}$ \\
\hline (1) fipronil 50g g/l SC & 800 & 8 \\
(2) fipronil & 1000 & 10 \\
(3) fenthion & 4500 & 45 \\
(4) Untreated control & & \\
\hline
\end{tabular}

the gallery counts, population counts as well as the percent infested stems was minimal as seen in the pre assessment (Figs. 1a, b). This was possible as the experimental plots were concentrated into areas where the initial infestation levels were consistent.

In all experimental plots the increasing trend in occupied galleries (Figure 1a), the corresponding population levels (total population) (Figure 1b) and also the percentage of infested stems (Figure 1c) was seen which is characteristic of the typical population trends observed in the field which in the middle of the current pruning cycle.

Though the trend was similar there was a difference in the numbers of galleries and the population between the treated and the untreated control where the treated plots had lower gallery and subsequent population counts compared to the control (Figure 1a and $b)(p<0.05)$. The post treatment counts were significantly different up to $6 / 7$ months after the treatment.

The percentage of control achieved with

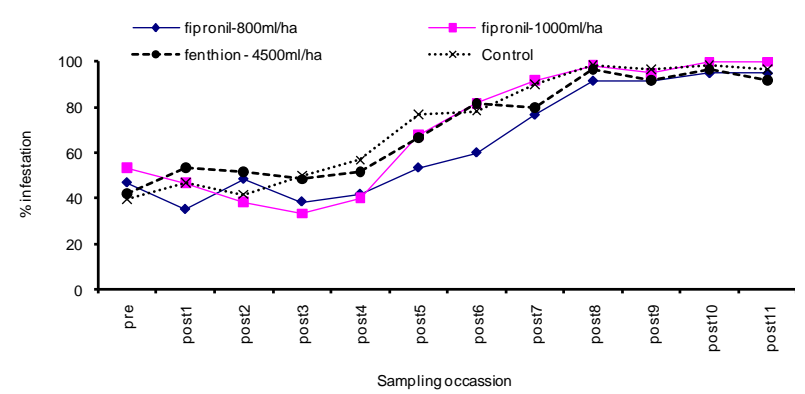

(c)

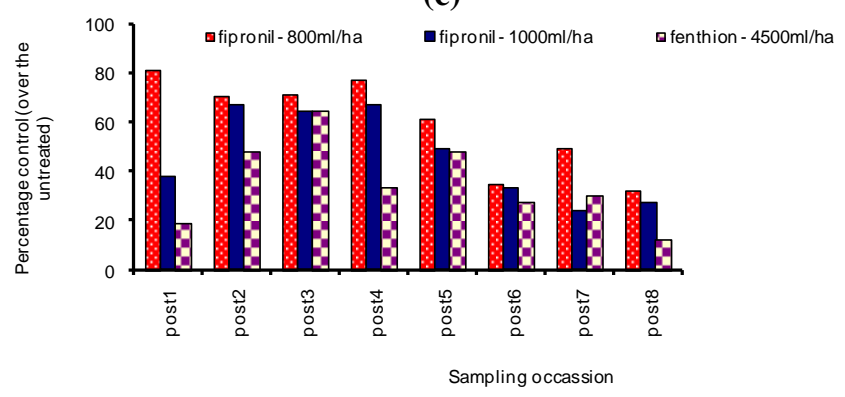

(d)

Figure 1. The trends in the formation of occupied galleries of Xyleborus fornicatus in untreated and treated plots (a), population numbers (b), percentage infested stems (c) and percent control achieved with time (d). 
Using these information the following parameters were calculated:

1. $\%$ infested stems per sample $=($ total number of infested stems in the sample/total number of stems per sample $) \times 100$

2. Average number of galleries per stem $=$ total number of galleries in the sample/ total number of stems per sample

3. Average population per stem $=$ total population in the sample/ total number of stems per sample

the two concentrations of fipronil was generally comparable which indicates that both concentrations are equal in effect, which varied in the range of $30-80 \%$ over the study period (Figure 1c). On the other hand, the percentage control obtained with the standard insecticide fenthion was marginally less than the control achieved with fipronil, the range varied between $20-60 \%$ over the study period (Figure 1c). This amounts to a control of about $40 \%$ and $50 \%$ on average by fenthion and fipronil respectively. The effect veins off after about 5 months suggesting the chemicals were not effective after that period (Figure 1d).

The rate of increase in the formation of galleries is significantly different between the treatment (fipronil $1000 \mathrm{ml} / \mathrm{ha}$ ) and that of the control (Figure 3a) and this is of practical importance as the low rates of increase in galleries reduces numbers of next generation and subsequently reducing the impact from the next generation of beetles. The results therefore, indicates that it is not possible to obtain a good prophylactic protection on the tea by the shot-hole borer with chemicals but rather reducing the impact of the next generation beetles on tea. However, the data of the Madulkelle experiment showed a somewhat different trend as the treatments with both chemicals did not prevent beetles entering the stems, which was evident in increased gallery formation after treatments (Figure 2a). On the other hand the increase in gallery numbers did not reflect in corresponding increase in the populations (Figure 2b). Mortality of the contaminated beetles would have taken place even after the bee-

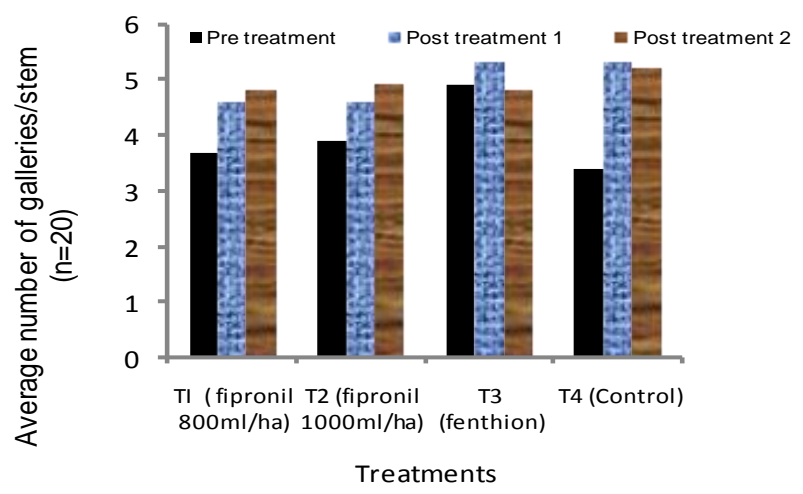

(a) tles excavated which could have been attributed to the low population numbers.

The results suggest that there is a difference in the rate of increase in gallery formation among the treatments with the higher dosage of and the control (Figure 3a). The rate is higher in the control plots than that of the Fipronil treated plots and the decline in gallery formation starts earlier in the control plots than the treated plots. This can be attributed to the fact that the saturation of stems with galleries takes place in control (untreated plots) before it happens in the treated stems.

The results showed that the decline in gallery numbers after an initial increase starts in the treated plot before it happens in the treated plots, which suggest that saturation of galleries in branches takes place in the untreated plots sooner than those in treated branches (Figure1a \& 3).

\section{DISCUSSION}

Control of shot-hole borer has been subject to a great deal of discussion from the time that the first discovery was made in later part of the $17 \mathrm{hth}$ century. The organochlorines have given a good control in the historical times but the present day organophosphates do not offer such a protection against this perennial pest problem. It is of paramount importance to highlight the aspects of 'control of shot-hole borer' on tea. The chemical, which can give a control against shot-hole borer, should be truly prophylactic as the damage is done it gets accumulated.

It is clear that the presently recommended insecticides the control achieved could be between 40 - 50\% but inadequate for a chemical employed

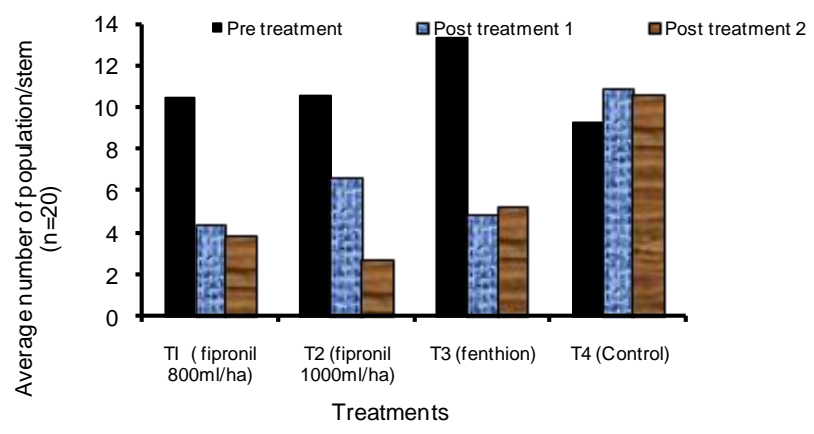

(b)

Figure 2: Change in gallery numbers (a) and population numbers between the treated and untreated plots (Madulkelle experiment) 


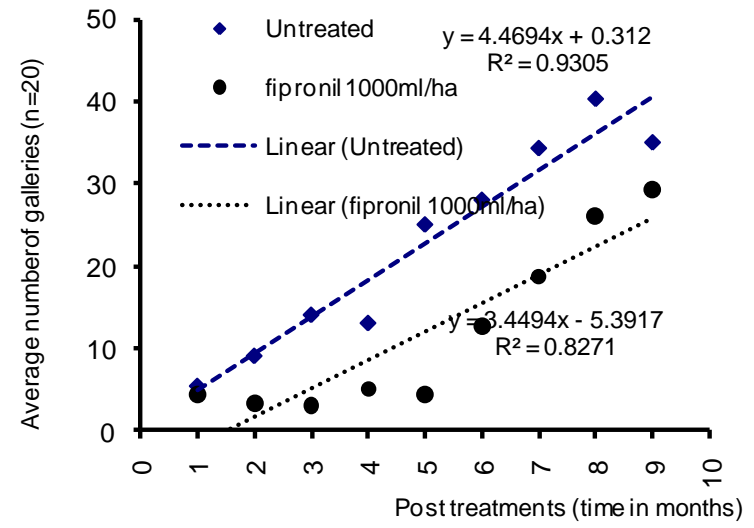

(a)

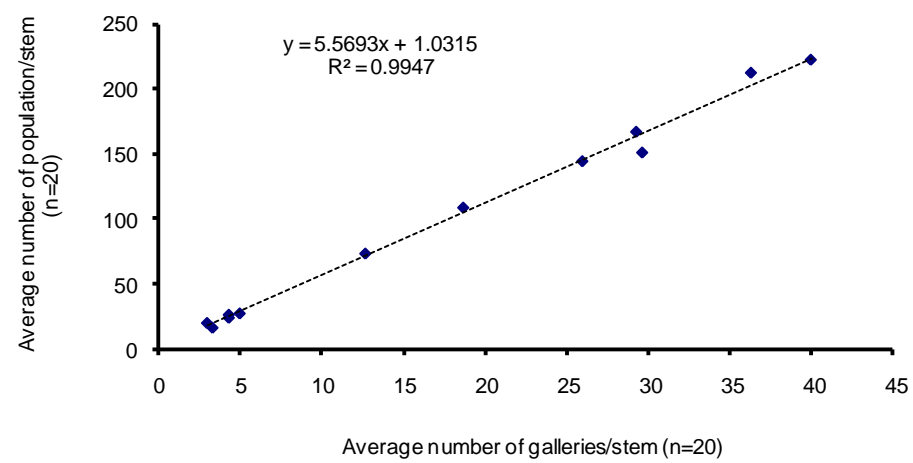

(b)

Figure 3. Rate of increase in occupied galleries of Xyleborus fornicatus after treatment (a) and correlation of gallery numbers and the population numbers in Regent ${ }^{\circledR}$ (fipronil)treated plots (b) (Ury experiment)

against this pest. The reduction in gallery numbers obviously resulted in reduction in population numbers as well. For example the maximum number of eggs encountered in a single gallery was about 35 (Gadd 1949) and if it is assumed that there is no mortality operating on this complement of eggs inside the gallery, the maximum number of beetles that can be expected to leave the gallery may be about the same. If the chemical can reduce the formation of galleries consequently the population of the next generation would also be reduced (Fig 3b).

The most important aspect of shot-hole borer damage to tea is the long term debilitation which is accelerated by the secondary causal organisms (Sivapalan 1976). As it is only the attack on the main primary branches that is likely to be contribute to the long term debilitation the reduction in gallery numbers, if not totally, would be beneficial in the long run. Prevention of heavy attacks on the basal parts of the main primary branches will, therefore, an important preventive measure.

It is therefore, clear that control of shot-hole borer requires a multi pronged approach. If the impact can be reduced with chemicals other methods can be used in combination to manage the shot-hole borer problem. Use of resistant cultivars and more importantly undertaking sanitation cleaning to reduce the impact of wood rot are some approaches that can be used to manage the pest problem and ensure sustainable bush health.

Fipronil has been removed from the current recommendation as a result of the very low MRL value specified by the European Union (EU).

\section{ACKNOWLEDGEMENTS}

The support given by the Managers and Assistant Managers of the Ury and Madulkelle, Estates is gratefully acknowledged.

\section{REFERENCES}

Cranham JE 1966 Shot-hole borer (Xyleborus fornicatus Eichh) of tea in Ceylon. Chemical control and population dynamics. Bull. Ent. Res. 56: 481-504.

Cranham JE, Danthanarayana W and Ranaweera JW 1962 The chemical control of Shot-hole borer with Dieldrin: Interim report on estate trials, 1960-1961. Tea Quart. 33: 5-33.

Gadd CH 1949 Studies of shot-hole borer of tea IV. Life cycle of the beetle. Tea Quart 20: 61-76.

Sivapalan P 1976 Control of shot-hole borer of tea (Xyleborus fornicatus Eichh.).Final Report on Research Conducted under Grant Authorized by US Public Law 480, The Tea Research Institute of Sri Lanka. pp 49-56.

Sivapalan P 1977 Population dynamics of Xyleborus fornicates Ecichhoff (Coleoptera: Scolytidae). Bull. Ent. Res 67: 329-335.

Vitarana SI 200375 years of Research in tea Entomology, Acarology and Nematology, In: Twentieth Century Tea Research in Sri Lanka (Ed.) WWD Modder, Ceylon Printers, Sri Lanka, pp 111163

Walgama RS and Pallemulla RMDT 2005 The Distribution of Shot-hole borer Xyleborus fornicatus Eichh. (Coleoptera: Scolytidae) Across Tea Growing Areas in Sri Lanka - A Reassessment. Sri Lanka Journal of Tea Sci. 70:105-120.

Walgama RS, Pallemulla RMDT, Liyanage DD, De Seram C and Jayathilake MM 2005 Shot-hole borer "Going up the hill". TRI UPDATE, Vol. 10, 4-5.

Walgama RS 2006 Pest Control vs Pesticide Residues: What Matters? Proceedings of the $213^{\text {th }}$ Experimental and Extension Forum, Tea Research Institute, Talawakelle, Sri Lanka. pp. 17-28. 